This is a self-archived version of an original article. This version may differ from the original in pagination and typographic details.

Author(s): Kiviniemi, Ulla; Tynjälä, Päivi; Heikkinen, Hannu L. T.; Martin, Anne

Title: Running a hybrid : mingling in-service and pre-service teachers in peer-mentoring groups

Year: 2021

Version: Accepted version (Final draft)

Copyright: (c) 2020 Taylor \& Francis

Rights: In Copyright

Rights url: http://rightsstatements.org/page/InC/1.0/?language=en

Please cite the original version:

Kiviniemi, U., Tynjälä, P., Heikkinen, H. L. T., \& Martin, A. (2021). Running a hybrid : mingling inservice and pre-service teachers in peer-mentoring groups. European Journal of Teacher Education, 44(4), 555-571. https://doi.org/10.1080/02619768.2020.1766442 


\title{
Running a Hybrid: Mingling In-Service and Pre-Service Teachers in Peer-Mentoring Groups
}

\author{
Ulla Kiviniemi* ${ }^{\text {a*, Päivi Tynjäläb }}{ }^{\mathrm{b}}$ Hannu L. T. Heikkinen ${ }^{\mathrm{b}}$ and Anne \\ Martin $^{\mathrm{a}}$
}

${ }^{a}$ Department of Teacher Education, University of Jyväskylä, Jyväskylä, Finland;

${ }^{b}$ Finnish Institute for Educational Research, University of Jyväskylä, Jyväskylä, Finland

*Corresponding author: Ulla Kiviniemi, Department of Teacher Education, P.O. Box 35 FI40014 University of Jyväskylä, Finland; ulla.kiviniemi@jyu.fi

Ulla Kiviniemi is a lecturer in art and craft pedagogy at the Department of Teacher Education, University of Jyväskylä (Finland). Her research interests are art and craft education, community art and professional development of teachers. (ORCID 0000-0003-1012-7673)

Päivi Tynjälä is a professor at the Finnish Institute for Educational Research, University of Jyväskylä (Finland). Her research area is learning and teaching in higher education. Her studies focus particularly on learning at the interface between higher education and working life, and the professional development of teachers.

Hannu L. T. Heikkinen is a professor at the Finnish Institute for Educational Research, University of Jyväskylä (Finland). His recent work has involved collaborative philosophical studies on wisdom as well as ecosystems for learning, including in higher education, learning for work and at work and professional development of teachers. (ORCID 0000-0003-25479372)

Anne Martin is a project researcher at the Department of Teacher Education, University of Jyväskylä (Finland). Her research interests are teachers' professional development, narrative research, and using creative writing methods to support professional development

\section{Disclosure statement}

No conflicts. 


\title{
Running a Hybrid: Mingling In-Service and Pre-Service Teachers in Peer-Mentoring Groups
}

\author{
This study examines a hybrid form of the Finnish Peer-Group Mentoring (PGM) \\ merging student teachers and in-service teachers of different career stages in \\ group meetings facilitated by an educated mentor. Experiences of the in-service \\ participants were studied by interviewing them, and the data were analysed \\ through thematic analysis. Four main themes were identified: 1) Enjoying group \\ activities, 2) Personal professional development, 3) Attaching to the professional \\ community and 4) Developing the teacher profession. The study shows that the \\ hybrid model of peer-group mentoring enables opportunities for teacher learning \\ that benefit both schools and teacher education institutions.
}

Keywords: teacher education; mentoring; professional development; intergenerational learning; thematic analysis

\section{Introduction}

The Finnish education system is well known for its highly educated teachers and extensive pedagogical freedom. On the one hand, the high degree of professional autonomy has often been accredited with the success of Finland in international student achievement tests, such as the evaluation by the Programme for International Student Assessment (PISA) (e.g., Hammerness, Ahtiainen, and Sahlberg 2017). On the other hand, a relatively low level of collaboration between teachers has been reported as being one of the main challenges facing the Finnish teacher education (OECD 2019; Taajamo, Puhakka, and Välijärvi 2019).

Another observed problem in teachers' professional development in Finland has been the lack of a seamless continuum and the need for integrating initial and in-service teacher education (Taajamo, Puhakka, and Välijärvi 2019). It has also been argued that teachers' professional development would benefit if it was better tied in with teachers' 
and organisations' everyday activities (Ministry of Education and Culture 2016; Heikkinen, Swachten, and Akyol 2015; Finnish National Agency for Education, 2014). In particular, a need for supporting new teachers following their graduation has been reported (Heikkinen et al. 2015). As a response to these concerns, a new model of professional development, Peer-Group Mentoring (PGM), has been developed in Finland to support the professional learning of teachers.

Globally, mentoring has generally been organised to support new teachers in their early career (Devos 2010; Wei et al. 2009), but research findings indicate that mentoring boosts professional development not only at the beginning of a career but also at its later stages (Huizing 2012). According to a literature review (Orland-Barak 2014), the culture, context and discourse plays a central role in many of the studies on mentoring; the meaning of the very concept of mentoring as well as the actual activities and actions that take place are actualised in different ways in different national contexts. Globally, the most common model of mentoring has been the dyad model, that is, pairing a mentee with a more experienced colleague (Kashiwagi, Varkey and Cook 2013; Orland-Barak 2014; Roberts 2000). In Finland, after having piloted traditional dyadic approaches to mentoring, collaborative forms of mentoring emerged through a series of action-oriented research projects (2003-2007). This development work was crystallised in the form of the Peer-Group Mentoring (PGM) model (Heikkinen, Jokinen, and Tynjälä 2012). This approach is not only about supporting beginning teachers but it also involves more experienced teachers at different stages of their career. In the present study, we examine a specific new form of peer-group mentoring, a hybrid model where pre-service and in-service teachers meet each other in mentoring groups. In the following sections, we first review studies on group type mentoring after which we introduce the hybrid model and our study in more detail. 


\section{Characteristics of peer-group mentoring}

While traditional mentoring is rooted in the concept of knowledge transmission from a more experienced worker (mentor) to the beginner (mentee) (Bozeman and Feeney 2007; Roberts 2000), peer-group mentoring builds on the concept of knowledge construction. Kroll (2016, p. 56) defines group mentoring as "a collection of three or more individuals, connected by their social relationship, distinctly gathered for the specific and shared purpose of intentionally challenging and supporting the others to enhance personal growth and professional skills/development of the others." The Finnish Peer-Group Mentoring model is in line with this definition. The model is based on theoretical ideas of socio-constructivism and dialogue (Heikkinen, Jokinen, and Tynjälä 2012; Kemmis et. al. 2014; Shabani 2016; Vygotsky 1978/1995). Shabani (2016) argues that Vygotsky's (1978/1995) sociocultural theory with the ideas of social mediation and the Zone of Proximal Development can be applied not only to students' learning but also to teachers' professional development. As regards group mentoring this leads to the assumption that participants of a group together can learn from each other more than as individuals alone or as dyads. This socio-constructivist approach to mentoring is actualised through building up professional knowledge of teaching work by sharing experiences, genuine problems and challenges as well as successful methods and practices between all of the participants of a group (Heikkinen et al. 2012; Geeraerts et al. 2015).

Models of peer support in the form of mentoring have been developed in several professional fields such as medicine (Chen et al. 2016; Pololi and Knight 2005), the military (Keller et al. 2005), industrial training (Emelo 2011), and higher education (Bozeman and Feeney 2007; Darwin and Palmer 2009; Skaniakos and Piirainen 2019). 
As regards teachers' peer-group mentoring, most of the studies have focussed on inservice teachers, but recently group mentoring has been organized also for pre-service teachers (Eriksson 2013, 2016; Yuan 2016). Studies on mixed groups of in-service and pre-service teachers are still rare. Previous studies of peer mentoring models have shown that the participants appreciate that peer relationships break hierarchical role division (Huizing 2012; Moss, Teshima, and Leszcz 2008), and that peer mentoring suits well in areas with fewer resources (Bussey-Jones et al 2006; Heikkinen, Jokinen and Tynjälä 2008). A review study on the Finnish model of PGM also showed that in addition to individual professional development, this kind of group learning may have indirect effects on the community level as well (Tynjälä et al. 2020).

Kroll (2017) has identified the following requisite participants characteristics for PGM: an intrinsic interest in the activity, a learning disposition, a commitment to participation, being comfortable with vulnerability, having courage to share problems with others, and a desire to support peers. Pennanen, Heikkinen and Tynjälä (2018) had similar findings when they examined participants' conceptions of the ideal mentor and mentee in the Finnish model of PGM. The study identified several characteristics that related to peerness and equality, active participation, and presence in the group.

\section{The Finnish model of peer-group mentoring for teachers}

Group-based mentoring may take place in different forms. In his review Huizing (2012) made a distinction between four types of group mentoring: 1) peer-group mentoring, where peers discuss without an assigned facilitator or mentor, 2) one-to-many group mentoring with an experienced mentor and a group of beginners, 3) many-to-one group mentoring, where two mentors meet a mentee regularly, and 4) many-to-many group mentoring, in which more than one experienced professionals and more than two less 
experienced colleagues discuss professional issues. The Finnish model can be described as a combination or mixture of these models. The peer-group mentoring groups are facilitated by experienced teacher-mentors who have completed a peer-group-mentor training programme for promoting reflective professional dialogue in a group of teachers. The composition of the participants may vary from new teachers only to a mixed group of experienced and less experienced colleagues.

The reflective dialogue is catalysed by participatory and creative methods utilising visual and literary materials to inspire discussion and reflection. One of the most important responsibilities of the mentor is to make sure that everybody's personal questions and issues will be given equal time and space in the meetings. Altogether, peer-group mentoring is an activity enabling teachers to share and reflect on their experiences, discussing problems and challenges they meet in their work and listening and encouraging one another. The aim of peer-group mentoring meetings is to promote the mutual professional development and well-being of teachers through collaborative self-development (Kemmis et al. 2014).

The Peer-Group Mentoring model reflects the Finnish educational culture, which is based on teachers' high autonomy and trust, and, accordingly, a key starting point in this approach is the assumption that teachers have the ability to examine their work collaboratively in groups. In its first meeting, the group determines the themes and pace of the meetings. The learning objectives of the group connect with the jointly agreed themes of the meetings. Learning in the groups is highly self-directed and utilises the personal competencies and interests of the group members. Accordingly, there are no assessments and the mentoring groups work on a voluntary and selfregulated basis (Heikkinen, Jokinen, and Tynjälä 2012). This approach on mentoring can also be understood in terms of Communities of Practices (CoP; Wenger and 
Wenger-Trayner 2011), although its theoretical basis derives from other sources, as described earlier. CoPs are known under various names, and the concept can be seen as a broad umbrella concept under which a wide variety of practices to support professional development can be placed.

During recent years, new forms of peer-group mentoring have been developed in Finland. One of the new developments is a kind of hybrid model of peer-group mentoring (Hybrid PGM), providing professional support and learning for both student teachers and in-service teachers. The Hybrid PGM puts into practice the principles of

integrative pedagogy (see Heikkinen, Jokinen, and Tynjälä 2012; Tynjälä 2008; Tynjälä et al. 2016) by combining different forms of knowledge in supporting the teachers' professional development. The professional group of teachers has its own culture, with its typical language, practices and tools. The participants share the "sociocultural knowledge" that has its roots in every school community. Hybrid PGM combines personal experiences and histories to the "practical knowledge" lived through in schoolwork. The theoretical concepts and models of educational science specify the common vocabulary providing terminologies and discourses for the teachers' professional orientation. The authentic and real-life professional narratives used in reflective activities deepen the conceptual understanding of the matters discussed. This reflection is also assumed to enhance participants" "self-regulative knowledge".

\section{Hybrid PGM: Pre-service and in-service teachers mingling in peer-mentoring groups}

In this study, we focus on the form of peer-group mentoring in which both pre-service and in-service teachers learn from each other. As described above, we call this form of mentoring Hybrid PGM. 
While the original model of teachers' Peer-Group Mentoring is targeted for inservice teachers, the Hybrid PGM initiative offers peer-group mentoring in mixed groups, where both in-service teachers and student teachers interact. Thus, the word 'hybrid' refers to mixing pre- and in-service teachers into the same PGM group. The pre-service teachers may have new pedagogical and theoretical knowledge to share, and, on the other hand, the in-service teachers can shed light on the every-day practices and challenges of teaching. Therefore, both have something to give and learn in Hybrid PGM groups. The aim is to bring about intergenerational learning and promote the lifelong professional development of teachers. As reported in a study by Geeraerts, Heikkinen, and Tynjälä (2018), the majority of teachers' learning takes place in the daily practice and discussions among the teacher colleagues. Respondents of that study indicated that learning occurred by collaborating and sharing information, knowledge and experiences, by providing and receiving advice and help, by observing, reflecting, imitating and participating, and by adjusting practices. The teachers reported that both younger and older teachers had had an impact on their professional identity work.

Teachers participate in the Hybrid PGM initiative voluntarily, in their spare time, and do not get any financial compensation for their participation. For student teachers, participation in the Hybrid PGM programme is rewarded by study credits. The teachers' work and personal experiences form the basis for the discussions in the peer-group mentoring groups. Hybrid PGM groups typically meet once a month to discuss work-related issues.

One of the key principles of Hybrid PGM is to combine informal and formal learning in flexible ways. In order to ensure the informal nature of the meetings, the groups often start with refreshments. The mentors serve coffee and facilitate the group meetings but they do not take the position of an expert. In other words, rather than being 
role models as in the traditional terms of mentoring, the mentors are facilitators enabling reflection in an equal setting also targeting and contextualising the discussion. In the first meeting, ethical principles of confidentiality, professionalism and commitment are to be agreed throughout the peer-group mentoring; which means that everything spoken stays in the group; the group discussions are limited to professional issues and the commitment to the whole procedure is underlined (Heikkinen, Jokinen, and Tynjälä 2008, 2012; Heikkinen, Kiviniemi, and Tynjälä, 2011; Kemmis et al. 2014; Korhonen, Heikkinen, and Kiviniemi 2015).

A previous study (Korhonen et al. 2017) examined the experiences of student teachers in the Hybrid PGM setting. It showed that the students appreciated a chance to meet in-service teachers and to discuss with them the questions that were occupying their minds concerning the teaching profession. However, even though the experiences were positive, the analysis revealed that the educational effect, powerfulness and complexity of the experiences of the students varied. Four different ways of experiencing the Hybrid PGM meetings were identified: (1) as a coffee break, (2) as peer support, (3) as identity construction, and (4) as a way of participating in a professional community (Korhonen et al. 2017). The purpose of the present study is to supply knowledge about Hybrid PGM by examining also in-service teachers' experiences.

\section{Context and aim of the research project}

Our study focuses on teachers' experiences of Hybrid Peer-Group Mentoring during the academic year 2015-2016. The six Hybrid PGM meetings we examined included a total of 10 in-service teachers, 14 student teachers and 6 mentors. The group meetings were held at different locations and the discussion themes arose from the interests and needs 
of the group members and varied between the groups. The structure of the meetings was more or less similar for all groups usually starting with informal chatting and sharing the most pressing news. While having some coffee and snacks, the groups discussed about the day's topic. The mentor might use some action-based exercises (idea cards, professional self-portrait drawing, one minute speech) to warm up the discussion. Sometimes one or two topical themes were introduced by incoming teachers and occupied some time to be dealt with.

One of the crosscutting themes throughout the groups was the new national curriculum that was put into practice in Finland in the autumn of 2016. In addition, the groups discussed professional topics, such as teachers' well-being and coping at work, teachers' responsibilities and freedom, roles of a teacher, working practices and curriculum development, collaboration with parents, pupil behaviour and teacher authority, collegial working habits, supportive networks and professional development.

In tandem with the described group meetings, the student teachers were involved in pedagogical school projects in classrooms of teacher participants. The aim of the project was to respond to genuine challenges in each teacher's daily work. The school projects involved various themes: history projects, publishing a class journal, practising ICT skills, entrepreneurship education, short-film making, school trip preparations, and live-action role-playing. When collaborating in these projects, the teachers would share their work experience and professional understanding with the student teachers.

While the preceding study (Korhonen et al. 2017) on the Hybrid PGM method focused on the participating student teachers' experiences, the aim of the present research was to examine mixed peer-group mentoring from the teachers' perspective. Thus, the following research question was addressed: How do in-service teachers experience peer-group mentoring in mixed groups with student teachers? 


\section{Research data and analysis}

Since the research aim was to examine mixed peer-group mentoring from the teachers' perspective, we interviewed eight teachers $(\mathrm{N}=10)$, who participated in mixed peergroup mentoring in the context of Hybrid PGM activities during the academic year 2015-2016. Two of the teachers refused to take part due to the busy springtime. All of the teachers were qualified and had at least a Master's degree. Each teacher possessed at least several years of work experience as a primary school teacher. All of the teachers except one were female.

The interviewer was a mentor-researcher with mentor training. The interviews were open-ended with the aim of capturing the participants' perceptions and descriptions, and an interview guide including a list of themes was used. The topics were: motivation for participating in Hybrid PGM, meaning given to mentoring, impressions of the meetings, discussion themes in the meeting sessions, links between theory and practice in mentoring activities, the quality of communication and interaction, and experiences of learning.

In the analysis, it was examined how teachers experienced participating in Hybrid PGM. The data were analysed through qualitative thematic analysis (Braun \& Clarke, 2006; 2019) in order to reveal the patterned meanings, or themes, across the teachers' experiences. The analysis focused on teachers' individual perceptions and experiences of participating in Hybrid PGM. According to Braun \& Clarke (2006), thematic analysis is well-suited for identifying and reporting certain patterns in data but it also requires a clear transparency and documentation of the analysis. There are various approaches to thematic analysis, but this analysis process can be described as reflexive (Braun \& Clarke, 2019). In other words, the themes were generated by the 
researchers through reflexing, discussing and engaging with the data, and the analysis was influenced by the researchers' and the context's theoretical backgrounds (Braun \& Clarke, 2016). The analysis process starts with familiarisation of the data and coding, and then moves on to generating initial themes, reviewing, defining and naming the themes, and finally, writing down the results of the thematic analysis with data extracts (Braun \& Clarke, 2006).

In practice, the participants' comments were cross-analysed and grouped into sub-themes to catch the total variation of perspectives concerning the central issues of the teacher talks. This assorted data was then re-analysed in order to identify elements that enabled determining sub-themes that condense and describe the interview data. In the second phase, these sub-themes were clustered into larger categories of main themes that were more abstract. These main themes were interpreted as the respondents' states of professionalism in their sociocultural context as teachers. The results of the reflexive thematic analysis are presented with quotations from the interviews. The data extracts have been translated from Finnish into English and the participants' names are pseudonyms.

\section{Results}

In the first phase of the analysis, we identified ten sub-themes that we then named illustratively to comprehensively represent the teachers' ways of experiencing Hybrid Peer Group Mentoring mentoring. The identified sub-themes were Relaxation and unwinding; Practical benefits; Expectations of systematic procedures; Memories of early career; Empowerment; Professional reflection; Sense of community; Strengthening communality; Professional affinity and Adopting a role of teacher educator. 
These sub-themes clustered into four main themes, depicting teachers' approaches to engaging in peer-group mentoring. The compressed main themes on how the teachers perceived peer-group mentoring in Hybrid PGM were:

\section{(1) Enjoying group activities}

(2) Personal professional development

(3) Attaching to the professional community

(4) Developing the teacher profession

These main themes are presented in the order of their scope, that is, from the narrower to broader conceptualisations. The main themes describe teachers' professional mindset and participation orientation in Hybrid PGM. The main themes can be seen as hierarchically structured, so that the first one listed represents the narrowest way of experiencing participation in a mixed peer-mentoring group and the last one represents the broadest perception. Each of these approaches is characterised by certain subthemes.

The first main theme immediately brings up positive feelings and emphasises the benefits of group meetings while stressing the importance of systematic procedures in organising activities. The second main theme focuses on the personal professional development of the teacher, whereas the third main theme expands from the individual to the social sphere by connecting the teacher to the school's work community and its developments. The fourth main theme encompasses the most advanced and broadest conceptualisation, that in which the teachers temporarily broaden their conception of teacher community over generations, valuing the continuity of the teacher profession and supporting new teachers' development. Below, the four main themes are described in more detail. The sub-themes related to the main themes are shown in italics. 


\section{Enjoying group activities}

This first main theme was characterised by three sub-themes. The sub-theme Relaxation and unwinding, relates to socialising and chatting with colleagues. The participants wanted to add pleasure to the meetings and feel comfortable in the mentoring group. For these teachers, the meetings provided a time and place for sharing the highlights or inflaming incidents of their schoolwork. Socialising and mixing with the group of colleagues was felt to be easy and everyone was keen to participate. Opening up to others and unwinding with refreshments created room for gathering strength as well as resting up.

It was, overall, a positive experience. At the beginning you do not know, whether it's a burden or a nice thing; but this was definitely a nice thing! - Helena (the names are pseudonyms).

Participation is easy: there are no requirements, no homework, no prerequisites, and no follow-up work. You just push yourself at the right time in the right place; it's so rare for a teacher! - Anna

And yes, drinking coffee is good as well. When you come in, you are tired after all, and so it is just wonderful to be served coffee. It is an absolute plus for coping. Helena

Second, the teachers experienced to get Practical benefits, such as gaining practical tips. The meetings widened their professional network and provided a place to meet other teachers outside their own schools. The peer group was likened to a temporary “teachers' room", filled with chats and discussions. However, as outlined, the discussions stayed strictly on the business during the meetings.

Especially if something was somehow acute for me, I could offload a bit...Helena 
Leaving behind the hullabaloo and confusion at school and having a meeting...

After the meeting, you left for home more serene and clear. - Hanna

In addition, concrete and practical tips were contrasted and elaborated and absorbed eagerly by participants for their own use. The school projects were shared with the other teachers in the group and acknowledged as valuable experiences. The in-service teachers expressed having received concrete help from their younger colleagues. The participants also felt that it was useful to share experiences and practices with teachers from other schools.

It is nice to hear what is being done at other schools and kind of compare and contrast it. Thus, you can somehow use it in your own work. - Emma

I gained something new and different for my own work; for example, the [other school] teacher gave me great ideas that I then tested and carried out in my class with many challenging pupils. - Irene

The participants' Expectations of systematic procedures were seen to be a prerequisite for enabling successful meetings. These expectations were closely related to practicalities, like choosing the meeting places and the meetings being scheduled precisely to enable participation in this activity.

There is a lot of rush in everyday life, but when the meetings were scheduled, well, it was all well-organised and we never felt as if in a hurry. - Anna

Using e-mail, we altered meeting times. We were all very flexible [...]. No one was ever absent. - Irene

In brief, the main theme of Enjoying group activities focuses on the teacher's personal needs and the benefits of peer-group mentoring in the teaching profession. This theme describes Hybrid PGM as a useful tool to advance discussions about daily school life and act as an extension of the "teachers' room". 


\section{Personal professional development}

The second main theme was labelled Personal professional development, since teachers' experiences in this category expanded toward more intentional professional reflection and development.

Memories of one's early career emerged when the teacher participants were reflecting on their personal professional history. Conversations in the peer groups raised nostalgic feelings and recollections of teachers' pre-service education and early career. Several of the teachers recounted good memories of an older colleague who had helped them somehow in their early career, for example. The teachers also heartily recognised the idealistic clang in the speech of the younger participants, although they were also sure that the forthcoming realities in teachers' work would shake the idealistic mind sets of the newly qualified teachers to some degree. Group discussions directed teachers to notice clearly how their teacher identities have crystallised and pedagogical skills have developed throughout their working career.

I remember that there was a lump in my stomach when I started as a teacher. It involved a wide range of issues that revolved around in school. - Otto

I also remember that teacher education does not really meet the needs of later working life in those first years. - Maria

The student teachers have a very romantic understanding of being a teacher. And with your 20-year career you know what realism is. - Irene

Under Empowerment sub-theme, teachers' stressed the satisfaction with themselves as professionals. They contrasted their early career and later work as a teacher and realised how much they already knew about their profession at this point in their career. This 
thought eased feelings of insufficiency and empowered the reliance on their own pedagogical professionalism.

And I learned, at least, to think of myself back at their stage. And then I realised how much I've learned! That became more visible. - Anna

In addition, I even noticed that, yes, I know a lot and master many things! Moreover, it is a pretty good feeling for a change. - Maria

In addition, educational theory and practice appeared in a new light. The teachers noticed how the theoretical teacher studies have amalgamated into their practice forming their professionalism.

I learned how the ideas of others fit into my thinking; how I could use the new ideas. We may have the same ideas, but nonetheless, we see things through our own glasses. - Emma

You do not think of background theories in everyday life [...] it is true that they [theories] shape your thinking. They create some kind of prioritisation that you don't contemplate as being theoretical but rather somehow as an order of priorities. - Maria

The colleagues in the meetings helped teachers to accept themselves as such teachers they are - with their individual attributes. Also different ways of being a teacher were accepted without hesitation. However, the empowerment did not eliminate selfexamination and then during the working week to ponder upon important issues.

This [Hybrid PGM] woke me up to realise that my thoughts are not so routine and that things can be dealt with in different ways, or things can be seen differently.Irene

Thus Professional reflection was characterised by practising active listening and reflective thinking. During hectic school days it is difficult to find peaceful moments for 
self-reflection. For example, during mentoring sessions, the teachers were sorting out their priorities and realising options; they felt that the discussions fuelled their thoughts and channelled their reflections. The diverse viewpoints were welcomed to challenge one's habitual routines and to reveal rigid patterns of thinking. Even some cynical thinking patterns were recognised.

However, we must remember that routines might be obsessional ways of doing [...] something you are not willing to alter. - Hanna

Hybrid PGM is a kind of mental training by which you can discover new perspectives and ideas. It mostly acts as a mirror, in a way. - Otto

Because of the informality student teachers often consulted in-service teachers on troublesome situations experienced in their practicums and temporary posts. The more experienced teachers praised their younger colleagues for their eagerness, lively activity, and extreme kindness toward their pupils, as well as their ICT skills. The young teachers' ease to identify with the lifestyle of their pupils_pop idols, gaming and entertainment — was also noticed.

They were so gentle toward the pupils. Sometimes, when pupils are challenging, I find it really annoying. It was soothing to see something like that. - Anna

In short, Personal professional development is about the ongoing identity work as a teacher: the acceptance of personal, subjective teacher qualities and approving the diverse qualities of other teachers.

\section{Attaching to the professional community}

The main theme Attaching to the professional community expanded from individual reflection to communality and collegial working habits. 
The sub-theme Sense of community mirrors the ideas of belonging to quite an intimate professional group. The experiences of the same kind of educational and professional backgrounds and similar professional interests united the group. The homogeneity of the group made it easy for teachers to opt in and to join the discussions during the sessions.

Every person spoke according to his or her own expertise, and that did not differ between pre- and in-service teachers. - Hanna

That was quite merciful of the teachers, not pretending to be something other than what they are. The others are facing the same kind of challenges and situations. Hanna

Hybrid PGM is a natural way to receive a new incoming teacher. For example, certain situations burden young and old teachers alike. - Otto

Participating the mentoring project broadened teachers' community from one school unit to other schools in the city. The participants felt that they could trust the group fellows and they spoke the same language.

In fact, I found out immediately at the beginning of my career that the teachers of the other classes knew instantly what I'm talking about [...]. And that kind of unites us all in the group. - Emma

Under the second sub-theme, Strengthening communality, the current and future school culture was seen as open and collaborative, emphasising sharing and working together.

It's good for us to work in pairs in our everyday work. I kind of force myself to stop and think about the day's important issues and prefer to wonder and think about them with someone else. I think we should do it more. - Maria 
Hybrid PGM meant sharing our own experiences and thoughts. But yes, the sharing was the most meaningful thing, the fact that we shared together and experienced together. - Irene

I see ICT as a great solution to many problems. Now we have the tools. We can network and work together online. - Otto

At the beginning of the hybrid mentoring approach, some of the teachers expressed having been a little afraid of the possible instrumental use of their attendance. They doubted whether they were invited only for the purpose of being prototypes or examples of a teacher to the students. However, these teachers soon realised that they were also getting a lot out of the meetings on a personal level.

Sometimes I thought we are perhaps there for the students. I would not say this was voluntary work or charity work. I rather feel that I got quite a lot out of it myself I hope the students received something, and hopefully they did. - Maria

Shortly, Attaching to the professional community is a collection of experiences of teachers emphasising the important role of sharing, co-operation and collaborative working habits of teachers. These experiences bring along emotional cohesion, which enhances communal work orientation and belonging to a specific professional group. This, in turn, facilitates the teacher's own satisfaction of belonging to the community.

\section{Developing the teacher profession}

The last main theme underlines the pride of belonging to the certain professional group and the willingness to engender and cultivate it further. Developing the teacher profession was considered as a signal of high professional ethos and advanced progression in one's work and it represents the deepest sentiment in Hybrid Peer-Group Mentoring. 
The sub-theme of Professional affinity includes feelings of emotional togetherness and the desire to welcome the next generation of teaching professionals. It also includes the will to safeguard and take care of the novices and current colleagues. In addition, the contact with the university and being part of the teacher education were perceived as important.

[I wanted] to support them [student teachers] at the beginning of their career and to provide them with new perspectives on teachers' work. - Emma

[Hybrid PGM] facilitates the transition from the study phase to working life, I feel. When I started out I began my schoolwork unprepared, just looking for unspoken, tacit knowledge, and consequently learned many things the hard way. So this may spare others such hard efforts, perhaps. - Helena

In the interviews, the teachers often brought up the desire to guide the students. The sub-theme, Adopting a role of teacher educator, includes taking in the younger teacher generation and sharing the accumulated tacit knowledge with them, such as by raising troublesome issues and situations during the discussions.

We [in-service teachers] chose conversation themes that we have actually experienced to be burdensome ... that's why we considered it significant to discuss these important issues with the students. - Maria

At the same time, we lessened students' excitement and pressures. - Otto

The participating teachers were pleased to detect that current teacher education connects theoretical studies and working life experiences. The joint professional continuum was emphasised. The teachers were eager to share their acquired expertise with the new teachers and be open to the new input of other professionals. 
I think of polyphony, and it is a pretty good word. I am fascinated by how cooperation happens; how we are acting on the same level and try to understand one another. - Hanna

I would call it peer learning, being open to the ideas of others and doing one's bit - a think tank. Everyone brings a log, so to speak, and puts it on the fire of thoughts, which creates either one large bonfire or a sprawling fire that goes in different directions and spreads, so to speak. - Emma

In sum, the main theme of Developing the teacher profession highlights the differences in the experiences between the student teachers and in-service teachers in the mixed peer-mentoring groups. The experienced teachers' educational urge encouraged them to share their experiences with the novices and to adopt the role of a teacher educator in certain moments while the student teachers were more cautious to actively advance the profession.

\section{Discussion}

In this study, we examined teachers' experiences of Hybrid Peer Group Mentoring merging student teachers and in-service teachers of different career stages. The purpose was to find out how the teachers experienced participation in the Hybrid PGM initiative and what kinds of professional development opportunities were built during the procedures. We identified four main themes describing the teachers' thinking during their one-year participation in Hybrid PGM. The scope of how teachers perceived their professional practices varied from individual and practical thinking to communal and ideological thinking. The main themes were labelled: 1) Enjoying group activities, 2) Personal professional development, 3) Attaching to the professional community, and 4) Developing the teacher profession. The themes form a cumulative continuum from the narrowest to the broadest way of seeing the profession in relation to the peer-group 
mentoring approach. Each category deepens and expands teachers' conception of the role of mixed peer-group mentoring in teachers' work.

Similar to the findings of another study on student teachers partaking in the same approach (Korhonen et al. 2017), there were differences between the in-service teachers' experiences. However, all of the experiences were positive, and it was clear that the Hybrid PGM meetings deepened the teachers' professional reflection and elevated their feelings of self-confidence. The participation also broke down and renewed professional stereotypes of teachers and enhanced professional collaboration between different teacher generations, as outlined in the National Development Programme for Teachers (Ministry of Education and Culture, 2016). Hybrid PGM thus offers in-service teachers a platform for developing their professional identities and refreshing their connection to current modes of teacher education.

The teachers experienced that Hybrid PGM generated well-being at work on their part. At the same time, it created significant learning possibilities for student participants through the mentoring meetings and on-the-job learning at school with inservice teachers. The teachers also felt that the soon-to-qualify young teachers smoothly updated their everyday practices when the pre-service teachers were working as resource teachers in matched pairs alongside the in-service teacher at school. Thus, the student teachers had the longed-for opportunity to step into the "real life" experience of being a professional teacher. The School Project component of the Hybrid PGM activities was executed in a very informal way without inspection or supervision. The results of this study imply that the informality does not water down the learning. Thus, this finding also invites further study initiatives regarding the School Project module of the Hybrid PGM.

One limitation of our study is the small number of participants. However, a 
qualitative study consisting of 88 pages of transcribed interviews can be seen as being based on a reasonable amount of data. Furthermore, what is more important than the actual sample size in qualitative research is the saturation point, that is, the point when increasing the sample size does not produce any new information or viewpoints. According to Mason (2010), the appropriate sample size in qualitative studies may vary between 5 and 20 participants, and some researchers have reported a saturation point with as few as 7 to 11 participants (Täks et al. 2014; Täks 2015; on sample size in qualitative studies, see also Trigwell 2000; Åkerlind 2008). When analysing the interview data in the present study, we noticed saturation by the time of the sixth/seventh participant. Thus, we believe that the study was able to assess, if not all variation, at least the main variations between teachers' experiences. Still, further studies with a higher number of participants would be valuable.

Theoretically, the present study brings new insight into research on teacher development by presenting a new cross-generational development model, Hybrid PGM, and a conceptualisation of the participating teachers' experiences of the model. The result of this study can be regarded as a textbook example of the benefits of intergenerational learning, where younger generations of teachers learn from their older colleagues and vice versa (Geeraerts et al. 2016). Our study, alongside the previous study (Korhonen et al. 2017), clearly shows that peer mentoring in mixed groups enables the professional development of teachers at all career stages. Regarding practical value, the findings, together with the aforementioned study, show that the Hybrid Peer-Group Mentoring model offers promising opportunities for designing hybrid teacher development programmes for the benefit of pre- and in-service teachers. This hybrid model is also a promising way to increase co-operation between universities and schools. However, further studies with higher numbers of participants and larger 
datasets are recommended. Actually, the Hybrid PGM model is being piloted in six universities in 2017-20 in Finland within the national Teacher Education Development Programme (2016). A deeper understanding of participants' experiences would help developers of teacher education to utilise the benefits and affordances of hybrid models for teacher learning. Based on these findings, we recommend the Hybrid PGM approach to be developed and researched further in different national, political and geographical settings.

Disclosure statement: No potential conflict of interest was reported by the authors.

\section{References}

Åkerlind, G. S. 2008. “Growing and developing as a university teacher.” Higher Education 55: 241-254. https://link.springer.com/content/pdf/10.1007\%2Fs10734-0079052-x.pdf.

Bozeman B. \& M.K. Feeney. 2007. "Toward a useful theory of mentoring: a conceptual analysis and critique.” Administration \& Society 39 (6): 719-739. doi:10.1177/0095399707304119.

Braun, V., \& Clarke, V. 2006. "Using thematic analysis in psychology.” Qualitative Research in Psychology 3 (2): 77-101. doi: 10.1191/1478088706qp063oa.

Braun, V., \& Clarke, V. 2016. "(Mis)conceptualising themes, thematic analysis, and other problems with Fugard and Potts' (2015) sample-size tool for thematic analysis.” International Journal of Social Research Methodology 19 (6): 739-743, doi: 10.1080/13645579.2016.1195588.

Braun, V., \& Clarke, V. 2019. "Reflecting on reflexive thematic analysis." Qualitative research in sport, exercise and health 11 (4): 585-597, doi: 10.1080/2159676X.2019.1628806. 
Bussey-Jones J, Bernstein L, Higgins S, Malebranche, D., Paranjape, A., Genao, I., Lee, B. \& Branch, W. 2006. "Repaving the road to academic success: The IMeRGE approach to peer mentoring." Academic Medicine 81 (7): 674-679.

Chen, M.M., Sandborg, C.I., Hudgins, L., Sanford, R., \& Bachrach, L.K. 2016. "A Multifaceted Mentoring Program for Junior Faculty in Academic Pediatrics." Teaching and Learning in Medicine 28 (3): 320-328. doi: 10.1080/10401334.2016.1153476.

Darwin, A. \& Palmer, E. 2009. "Mentoring circles in higher education.” Higher Education Research and Development 28 (2): 125-136. doi: 10.1080/07294360902725017.

Devos, A. 2010. "New teachers, mentoring and the discursive formation of professional identity." Teaching and Teacher Education 26: 219-1223. doi: 10.1016/j.tate. 2010.03 .001 .

Emelo, R. 2011. “Group mentoring: rapid multiplication of learning.” Industrial and Commercial Training 43(3): 136-145. doi: 10.1108/00197851111123587.

Eriksson, A. 2013. "Positive and negative facets of formal group mentoring: Preservice teacher perspectives.” Mentoring \& Tutoring: Partnership in Learning 21(3): 272-291. https://doi.org/10.1080/13611267.2013.827834.

Eriksson, A. 2016. "Pre-service teachers' questions about the profession during mentoring group conversations.” European Journal of Teacher Education 40 (1): 76-90. https://doi.org/10.1080/02619768.2016.1251901.

Finnish National Agency for Education. 2014. Opettajankoulutuksen tilannekatsaus. Tilannekatsaus marraskuu 2014. [Status of Teacher Education. Progress Report, November 2014.] (Eds.) Seija Mahlamäki-Kultanen, Anneli Lauriala, Asko Karjalainen, Anneli Rautiainen, Mari Räkköläinen, Elisa Helin, Petri Pohjonen, \& Kari 
Nyyssölä. Muistiot 2014: 4. Accessed 9 April 2018.

http://www.oph.fi/download/163626_opettajankoulutuksen_tilannekatsaus.pdf.

Geeraerts, K., Heikkinen, H., \& Tynjälä, P. 2018. ’Intergenerational learning of teachers: What and how teachers learn from younger and older colleagues." European Journal of Teacher Education 41(4): 479-495. doi: 10.1080/02619768.2018.1448781.

Geeraerts, K., Tynjälä, P., Markkanen, I., Pennanen, M., Heikkinen, H., \& Gijbels, D. 2015. "Peer-Group Mentoring as a Tool for Teacher Development." European Journal of Teacher Education 38 (3): 358-377. https://doi.org/10.1080/02619768.2014.983068.

Geeraerts, K., Vanhoof, J., \& Van den Bossche, P. 2016. “Teachers' perceptions of intergenerational knowledge flows." Teaching and Teacher Education 56: 150-161. doi: 10.1016/j.tate.2016.01.024.

Hammerness, K., Ahtiainen, R., \& Sahlberg, P. 2017. Empowered educators in Finland: How high-performing systems shape teaching quality. San Francisco: JosseyBass. Accessed 9 April 2018.

https://www.dawsonera.com/readonline/9781119372172/startPage/5/1.

Heikkinen, H.L.T., J. Aho and H. Korhonen (2015). Ope ei saa oppia: Opettajankoulutuksen jatkumon kehittäminen. [Teacher learns not: Development of teacher education continuum.] University of Jyväskylä: Finnish Institute for Educational Research.

Heikkinen, H., Jokinen, H., \& Tynjälä, P. 2008. "Reconceptualising mentoring as a dialogue.” In G. Fransson \& C. Gustavsson (Eds.) Newly qualified teachers in Northern Europe. University of, Teacher Education, Research Publication 4: 107-124. ). Gävle: University of Gävle.

Heikkinen, H., Jokinen, H., \& Tynjälä, P. 2012. "Teacher education and 
development as lifelong and lifewide learning.” In H. Heikkinen, H. Jokinen \& P. Tynjälä (Eds.) Peer-Group Mentoring for Teacher Development (3-30). London and New York: Routledge.

Heikkinen, H., Kiviniemi, U., \& Tynjälä, P. 2011. “Integrative Pedagogy in Practicum: Meeting the Second Order Paradox of Teacher Education.” In M. Mattsson, T. V. Eilertsen, \& D. Rorrison (Eds.) A Practicum Turn in Teacher Education (91-112). Rotterdam: Sense.

Heikkinen, H., Swachten, L., \& Akyol, H. (Eds.) 2015. Bridge over troubled water: New perspectives on teacher induction. Ankara: Pegem Akademi.

Huizing, R.L. 2012. "Mentoring Together: A Literature Review of Group Mentoring." Mentoring \& Tutoring: Partnership in Learning 20 (1): 27-55. doi: 10.1080/13611267.2012.645599.

Kashiwagi, D. T., Varkey, P.Cook, D.A. 2013. "Mentoring Programs for Physicians in Academic Medicine. A Systematic Review." Academic Medicine 88(7): 1029-1037. doi: 10.1097/ACM.0b013e318294f368.

Keller, R.T., Greenberg, N.,Bobo, W.V., Roberts, P., Jones, N., Orman, D.T. 2005. "Soldier Peer Mentoring Care and Support: Bringing Psychological Awareness to the Front" Military Medicine 170 (5): 355-361. https://doi.org/10.7205/MILMED.170.5.355.

Kemmis, S., Heikkinen, H., Fransson, G., Aspfors, J., \& Edwards-Groves, C. 2014. "Mentoring of new teachers as a contested practice: Supervision, support and collaborative self-development." Teaching and Teacher Education 43: 154-164. https://doi.org/10.1016/j.tate.2014.07.001.

Korhonen, H., Heikkinen, H. L. T., \& Kiviniemi, U. 2015. “Peer-group mentoring in Finland.” In H. L. T. Heikkinen, L. Swachten, \& H. Akyol (Eds.), Bridge 
over troubled water: New perspectives on teacher induction (122-146). Ankara: Pegem Akademi.

Korhonen, H., Heikkinen, H. L. T., Kiviniemi, U., \& Tynjälä, P. 2017. ’Student teachers' experiences of participating in mixed peer mentoring groups of in-service and pre-service teachers in Finland." Teaching and Teacher Education 61: 153-163. https://doi.org/10.1016/j.tate.2016.10.011.

Kroll, J. 2016. "What Is Meant By The Term Group Mentoring?” Mentoring \& Tutoring: Partnership in Learning 24 (1): 44-58. doi: 10.1080/13611267.2016.1165488.

Kroll, J. 2017. "Requisite participant characteristics for effective peer group mentoring.” Mentoring \& Tutoring: Partnership in Learning 25 (1): 78-96. doi: 10.1080/13611267.2017.1308096.

Mason, M. 2010. "Sample size and saturation in $\mathrm{PhD}$ studies using qualitative interviews.” Forum: Qualitative Social Research 11(3): art. 8. Accessed 9 April 2018. http://www.qualitativeresearch.net/index.php/fqs/article/view/1428/3027.\%20\%20\%20\%20\%5BA.

Ministry of Education and Culture 2016. Opettajankoulutuksen kehittämisen suuntaviivoja. Opettajankoulutusfoorumin ideoita ja ehdotuksia. [Guidelines for Developing Teacher Education. Teacher Education Forum. Ideas and Suggestions.] Opetus- ja kulttuuriministeriön julkaisuja 2016:34. Accessed 9 April 2018. http://minedu.fi/documents/1410845/4583171/Opettajankoulutuksen+kehitt\%C3\%A4m isen+suuntaviivoja+-+Opettajankoulutusfoorumin+ideoita+ja+ehdotuksia .

Moss, J. Teshima, J. \& Leszcz, M. 2008. "Peer group mentoring of junior faculty.” Academic Psychiatry 32: 230-235. doi: 10.1176/appi.ap.32.3.230.

OECD (2019). TALIS 2018 Results (Volume I): Teachers and School Leaders as Lifelong Learners. Paris: OECD Publishing. doi: 10.1787/1d0bc92a-en. 
Orland-Barak, L. 2014. "Mediation in Mentoring: A Synthesis of Studies in Teaching and Teacher Education.” Teaching and Teacher Education 44: 180-188. doi: 10.1016/j.tate.2014.07.011.

Pennanen, M., Heikkinen, H., and Tynjälä, P. 2018. Virtues of mentors and mentees in the Finnish model of teachers's peer-group mentoring. Scandinavian Journal of Educational Research. doi: 10.1080/00313831.2018.1554601.

Pololi, L \& Knight, S. 2005. "Mentoring faculty in academic medicine. A new paradigm?” Journal of General Internal Medicine 20: 866-870. doi: 10.1111/j.15251497.2005.0167.x.

Roberts, A. 2000. "Mentoring revisited: a phenomenological reading of the literature." Mentoring \& Tutoring 8 (2): 145-170. https://doi.org/10.1080/713685524.

Shabani, K. (2016). “Applications of Vygotsky’s sociocultural approach for teachers' professional development.” Cogent education 3 (1). https://doi.org/10.1080/2331186X.2016.1252177.

Skaniakos, T. \& Piirainen, A. 2019. "The meaning of peer group mentoring in the university context." International Journal of Evidende-Based Couching and Mentoring 17 (1): 19-33. doi: 10.24384/EKNZ-S730.

Taajamo, M., \& Puhakka, E. (2019.) Opetuksen ja oppimisen kansainvälinen tutkimus TALIS 2018. Perusopetuksen vuosiluokkien 7-9 ensituloksia, osa 1. [International Study of Teaching and Learning TALIS 2018. First results for primary education grades 7-9, part 1.]. Raportit ja selvitykset 2019:8. Helsinki: Finnish National Agency for Education.

Täks, M. 2015. Engineering students' experiences of entrepreneurship education: A qualitative approach. (Doctoral dissertation, University of Tartu, Tartu). Accessed 9 April 2018. http://dspace.ut.ee/handle/10062/45901. 
Täks, M., Tynjälä, P., Toding, M., Kukemelk, H., \& Venesaar, U. 2014. “Engineering students' experiences of studying entrepreneurship.” Journal of Engineering Education 103 (4): 573-598.

https://onlinelibrary.wiley.com/doi/abs/10.1002/jee.20056.

Trigwell, K. 2000. “A phenomenographic interview on phenomenography.” In J. A. Bowden \& E. Walsh (Eds.) Phenomenography (62-82). Melbourne: RMIT University Press.

Tynjälä, P. 2008. "Perspectives into learning at the workplace.” Educational Research Review 3: 130-154. https://doi.org/10.1016/j.edurev.2007.12.001.

Tynjälä, P., Pennanen, M., Markkanen, I. and Heikkinen, H.L.T. 2020. Finnish model of peer-group mentoring: review of research. Ann. N.Y. Acad. Sci.. doi:10.1111/nyas.14296.

Tynjälä P., Virtanen, A., Klemola, U., Kostiainen, E., \& Rasku-Puttonen, H. 2016. "Developing social competence and other generic skills in teacher education: Applying the model of integrative pedagogy.” European Journal of Teacher Education 39 (3): 368-387. https://www.tandfonline.com/doi/full/10.1080/02619768.2016.1171314 . Vygotsky, L. (1978/1995). Mind in society: The development higher psychological processes. (M. Cole, V. John-Steiner, S. Scribner, \& E. Souberman, Eds., and Trans.). Cambridge, MA: Harvard University Press.

Wei, R. C., Darling-Hammon, L., Andree, A., Richardson, N., \& Orphanos, S. 2009. Professional learning in the learning profession: A status report on teacher development in the U.S. and abroad. Technical report. Dallas, TX: National Staff Development Council.

Wenger, E. \& Wenger-Trayner, B. (2011). Communities of practice: A brief 
introduction. (Online version.) Accessed 10 Feb 2020. https://wenger-trayner.com/wpcontent/uploads/2015/04/07-Brief-introduction-to-communities-of-practice.pdf.

Yuan, E.R. 2016. “The dark side of mentoring on pre-service language teachers' identity formation." Teaching and Teacher Education 55: 188-197. doi:

https://doi.org/10.1016/j.tate.2016.01.012. 